\title{
Knowledge Exchange Partnerships on Global Citizenship Education at Bridge 47 - Building Global Citizenship
}

\section{Talía Vela-Eiden'}

How do you bring together academics, practitioners, and policymakers to advocate and partner for Global Citizenship Education? This is what EADI and Bridge 47 do with partners from all over Europe for a common goal, to promote transformative change in society.

\section{About Bridge 47}

The Bridge 47 - Building Global Citizenship project mobilises global civil society to contribute to global justice and eradication of poverty through Global Citizenship Education (GCE). The project provides a space for civil society organisations, activists, and other interested people to interact with one another, exchange information and resources and develop new and innovative approaches for global citizenship education. The project focuses on joint advocacy efforts and building new partnerships, while it also supports civil society to develop new approaches to reaching out to new stakeholders and provides tools to promote and act upon Global Citizenship in the context of Sustainable Development Goal (SDG) 4. The project works closely with partners engaged in informal and non-formal education and life-long learning with a view to promoting transformative change in society.

\footnotetext{
${ }^{1}$ Knowledge Exchange Partnerships Officer, EADI - European Association of Development Research and Training Institutes and Bridge 47 - Building Global Citizenship
} 


\section{About EADI}

EADI, the European Association of Development Research and Training Institutes, takes the leading role in the work on Knowledge Exchange Partnerships which promotes a flow of information and best practices between research institutions and civil society organisations. This is done by building new and strengthening existing regional partnerships. With a series of events, workshops, and conferences over the next years, we are contributing to bridge gaps between civil society organisations and academia. The regional Knowledge Exchange Partnerships in lberia, Northern Europe and Southern-Eastern Europe countries are open to interested civil society organisations and academic institutions.

\section{SDG 4.7}

The United Nations 2030 Agenda considers education central in achieving the Sustainable Development Goals (SDGs) and for the first time at the global level, recognises that parallel efforts are needed to ensure that all lifelong learners, of different ages and backgrounds, acquire the knowledge and skills to promote sustainable development as outlined in detail by SDG 4.7. Working towards this goal, the Bridge 47 project facilitates the implementation of this target and i) aims at developing and promoting successful policies and practices concerning new and innovative ways of reaching out to the wider society and ii) responds to the focus shift from formal education to informal and non-formal education and invites us to rethink the knowledge, skills, and capacities we all need as world citizens.

\section{Global Citizenship Education}

GCE is a term used by civil society to describe processes to create global change and justice. It is defined by UNESCO (United Nations Educational, Scientific and Cultural Organization) as:

Global Citizenship Education (GCED) aims to empower learners of all ages to assume active roles, both locally and globally, in building more peaceful, tolerant, inclusive and secure societies (Website UNESCO, 2018).

Global Citizenship Education is an integral part of Goal 4 of the SDGs: "Ensure inclusive and equitable quality education and promote lifelong learning opportunities for all". The specific target within the SDGs reads as follows: 
Target 4.7: "By 2030, ensure that all learners acquire the knowledge and skills needed to promote sustainable development, including, among others, through education for sustainable developmentand sustainable lifestyles, human rights, gender equality, promotion of a culture of peace and non-violence, global citizenship and appreciation of cultural diversity and of culture's contribution to sustainable development." (A/RES/70/1, 2015: 17)

As the SDGs aim to be development global solutions to global problems, without having a specific distinction between developed and developing countries, they do address issues in the Global South as well as in the Global North.

Given the UNESCO definition of GCE, its incorporation into the SDGs and the overall objective of the Bridge 47 project: "(...) that global civil society is mobilised to contribute effectively to global justice and eradication of poverty through global citizenship" (Annex A.2, 2016: 4); GCE must be understood as an ambitious and broad concept that offers implications into a lot of different areas. Key areas can be defined as sustainable development, human rights, gender equality, human security, peace, and appreciation of cultural diversity.

Keeping it short, GCE educates to build a more just, peaceful, and equal world without leaving anyone behind.

\section{What are the Knowledge Exchange Partnerships of Bridge 47?}

EADI's work in Knowledge Exchange Partnerships is aimed at building bridges between national/regional developmenthigher education and research organisations and national/regional civil society actors. It is important to build upon already existing approaches of collaboration to develop a common space for exchanging and sharing between research and practice, in accordance with the message developed by Bridge 47 reflected in the Target 4.7 Roadmap. The partners shall contribute from their different perspectives, from ideas to action and from practical work to further research. Partnerships might lay the ground for the identification and formulation of needs for future research and action/practice.

EADI focuses on building partnerships ensuring an information flow and exchange of best practices between academia and civil society. Knowledge Exchange Partnerships are examples that could be replicated. EADI's focus will be on regional European Knowledge Exchange Partnerships, while that does not exclude partnerships without a specific regional focus. 
The Knowledge Exchange Partnerships serve to bridge the gap between academia and civil society. As described, the constant flow of ideas and best practices from both the practical and the theoretical side must be assured, respecting differences in culture, communication, and philosophy.

\section{Knowledge Exchange Partnerships in action}

EADI has implemented collaborative bridges in three regional European Knowledge Exchange Partnerships in the Bridge 47 project. Within the timeframe of the project, the partnerships are hosting events, on-site and online. EADI will bring them together in September 2020 for an online conference to debate local and regional dissemination on Global Citizenship in the context of SDG4 and learnings during the Bridge 47 project, plus best practices of cooperation between academia and civil society. The aim of the conference is to reflect and summarise on the processes and experiences of Knowledge Partnerships during the duration of the Bridge 47 project and wrap up recommendations for future research and action/practice.

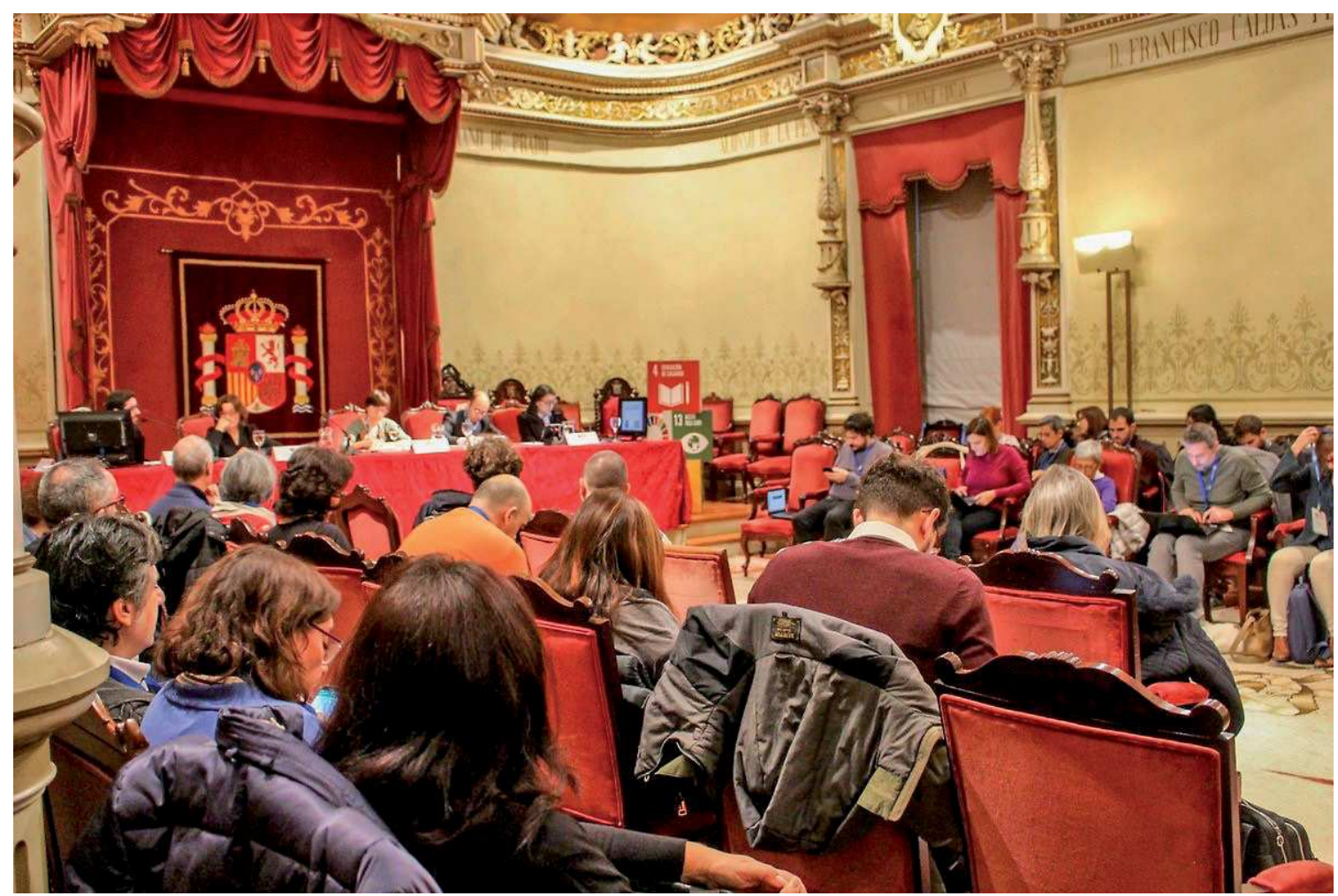


Besides regular meetings, the Bridge 47 Knowledge Exchange Partnerships are building the basis to develop a Massive Open Online Course (MOOC) to provide online learning on Global Citizenship in the context of SDG4, and to publish a Knowledge Exchange Partnership Manual to support those persons and organisations who want to set up their own Knowledge Partnerships in the future.

EADI's main aim is to link the work of researchers and practitioners, while disseminating and facilitating Global Citizenship exchanges and integrating the outcomes of the Bridge 47 Project among EADI's members through further activities towards ownership and replication of the Bridge 47 project products.

\section{Present Partners}

As of May 2020, EADI has entered partnerships with several higher education and civil society organizations, working together towards the building up of the Knowledge Exchange Partnerships of Bridge 47.

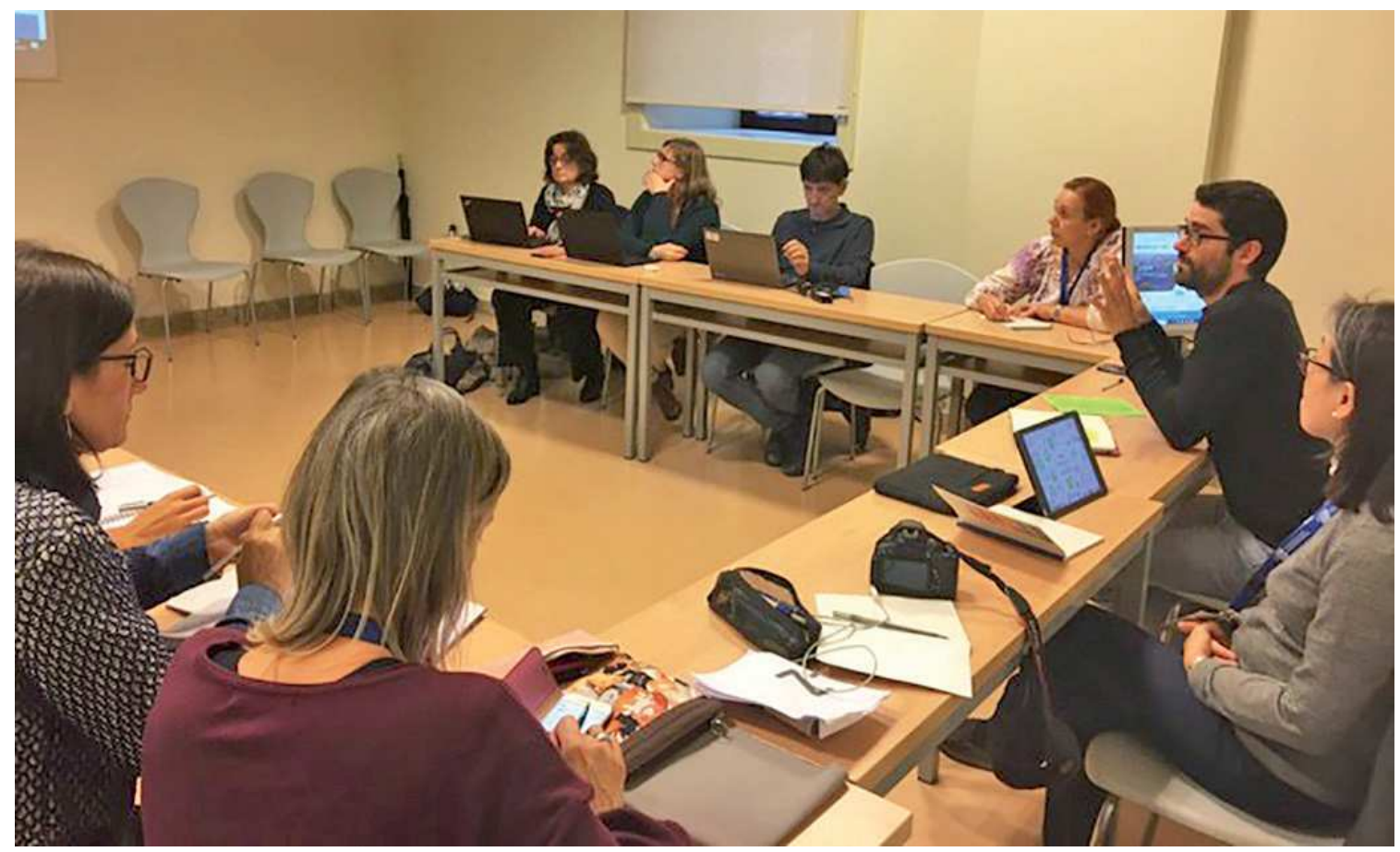

The Iberian Knowledge Exchange Partnership has as participants academics and civil society of Spain and Portugal. EADI's partners in these efforts are Fundación Etea (Spain) and the Sinergias ED community (Portugal). The first meeting took 
place in Córdoba (Spain) in December 2018 in cooperation with Fundación Etea. The second event was held in Santiago de Compostela (Spain) in partnership with the Universidade de Santiago de Compostela (Spain) in November2019. The third meeting took place online during May 2020 in cooperation with the Sinergias ED community.

The South Eastern Europe Knowledge Exchange Partnership has partners of Slovakia and Slovenia. EADI has joined Ambrela (Slovakia) and SLOGA (Slovenia), which are also members of the Bridge 47 consortium in this effort. In addition, EADI has signed a Memorandum of Understanding with Comenius University at Bratislava, Faculty of Social and Economic Sciences for the coordination of the knowledge partnership. The kick-off and second events took place in Bratislava (Slovakia) in May and December 2019 in cooperation with FSES-Comenius University at Bratislava. A third event will take place online the latest in July 2020.

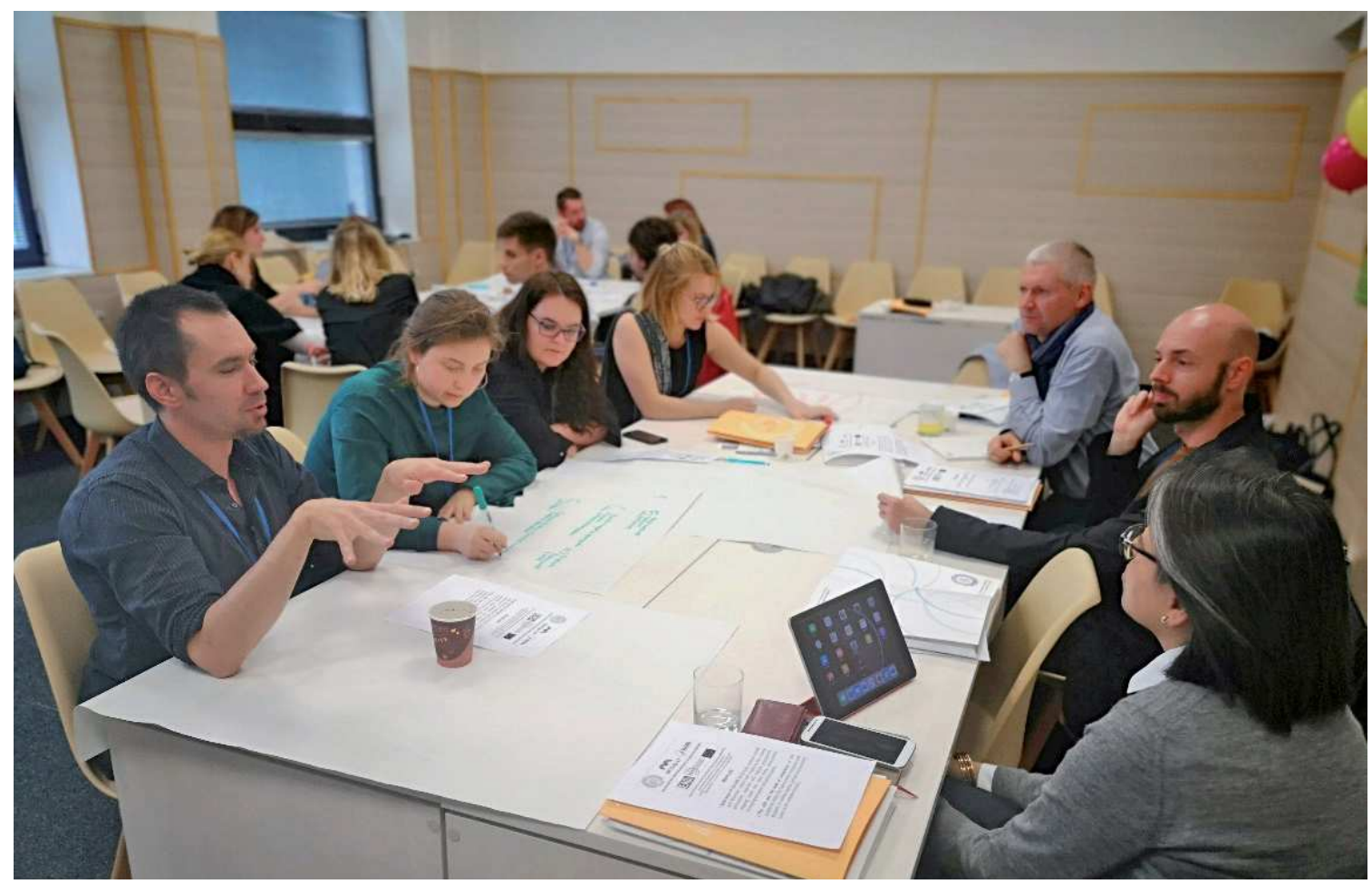

The Northern Europe Knowledge Exchange Partnership has as partners MUNDU (Denmark) and IDEA Scotland, which are also members of the Bridge 47 consortium. EADI has also signed a Memorandum of Understanding with the University of Stirling. The Liverpool World Centre is the coordination partner in this effort. The kick-off event took place in January 2020 in Stirling (Scotland) in cooperation with the University of Stirling. The second event will be online in June 2020. 


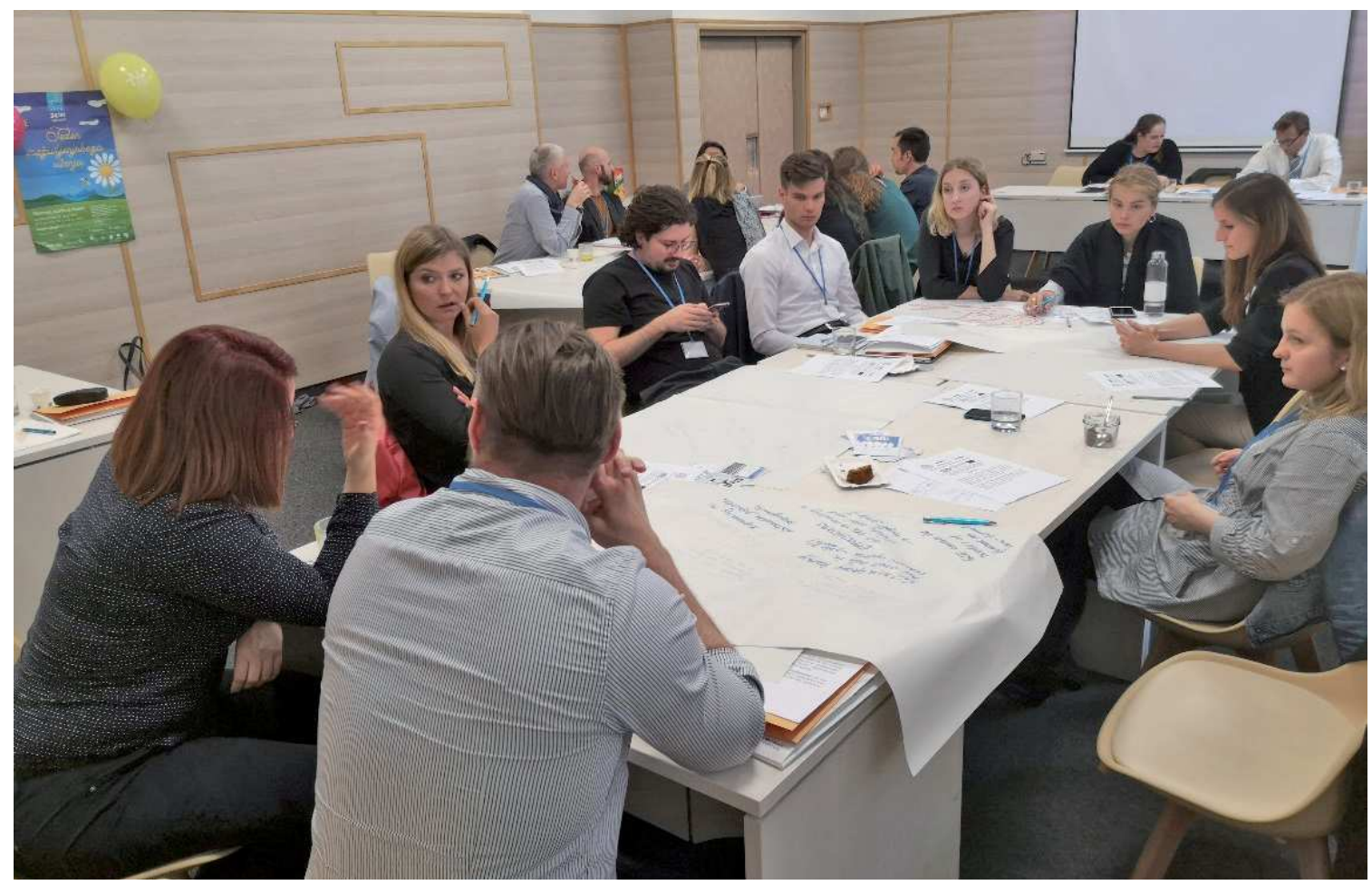

\section{Current Developments}

Presently, the meetings of the Knowledge Exchange Partnerships have moved online. Each partnership will be holding events until August 2020. The Bridge 47 Knowledge Exchange Partnerships Conference will take place online in September 2020.

As noted above, a Massive Open Online Course (MOOC) with an accompanying publication is being prepared. The coordination of this activity is overseen by Centro de la Cooperazione Internazionale (Italy). EADI expects to present the results at the end of the Bridge 47 project timeline.

\section{Contributions of the Knowledge Exchange Partnerships to Bridge 47}

The participants of the Knowledge Exchange Partnerships are active contributors in the events organized by the Bridge 47 Global Network and the Advocacy and Innovation initiatives of the project. Furthermore, members of the three regional 
knowledge partnerships were present in Helsinki in November 2019 for the process of drafting of the Target 4.7 Roadmap.

EADI will continue to give impulse to these contributions through Bridge 47 and its own larger networks of allies and partners. Moreover, collaborative initiatives for research and practice could be put in place by the participants of the partnerships in the following years.

For more information, visit:

https://www.eadi.org/bridge-47-building-global-citizenship/ 